\title{
Infância e Família: Desenvolvimento Infantil na Perspectiva da Fala-em-Interação
}

\author{
Childhood and Family: Child Development from a Talk-in-Interaction Perspective
}

\author{
Cristiane M. Schnack* \& Ana Cristina Ostermann \\ Universidade do Vale do Rio dos Sinos
}

\begin{abstract}
Resumo
O presente estudo apresenta a Análise da Conversa e discute como essa abordagem teórico-metodológica pode contribuir para o objetivo central do estudo, qual seja, o de compreender de que maneira a significação de infância está vinculada ao processo de socialização da linguagem e, por conseguinte, de desenvolvimento infantil. Investigam-se dados naturalísticos do cotidiano de duas famílias brasileiras. Constata-se que os significados culturais de infância nas famílias estudadas acabam também por definir espaços distintos de desenvolvimento infantil. Enquanto que em uma família a infância é vista como fase de transição e crescimento, em que os adultos esperam a criança crescer para que ela possa participar plenamente das atividades organizadas por eles, na outra família a infância é concebida como espaço de franca atividade, sendo as atividades dos adultos organizadas em função da criança.

Palavras-chave: Desenvolvimento infantil; Análise da fala-em-interação; Análise da conversa; Organização familiar; Infância.
\end{abstract}

\begin{abstract}
The current study presents the Conversation Analysis theoretical and methodological qualitative approach and discusses the ways through which it can contribute to the core goal of this study, which is, to understand how the signification of childhood is related to the process of language socialization and, thus, to child development. Naturally occurring data from two Brazilian families' daily routines are investigated. The cultural meanings related to childhood observed in the investigated families seem to define distinct spaces for child development. In one of the families, childhood is seen as a transitory stage in order to become a grown-up and, then, to be able to fully participate in the activities organized by adults. In the other family, childhood is understood as a stage in full development, in which adults' activities are organized regarding the child.

Keywords: Child development; Talk-in-interaction; Conversation analysis; Family organization; Childhood.
\end{abstract}

Estudos que se debruçam sobre a questão do desenvolvimento infantil e da aquisição da linguagem têm sido, cada vez mais, desenvolvidos por meio de pesquisas qualitativas a partir de dois enfoques essenciais: (a) a centralidade da interação verbal (e.g. Borges \& Salomão, 2003; Braz \& Salomão, 2002; Ervin-Tripp, 1979; Snow \& Ferguson, 1977) e (b) a relevância cultural dos grupos estudados (e.g. M. Goodwin, 2007; Ochs \& Schieffelin, 1986; Rogoff, 2003; Schieffelin \& Ochs, 1986). Neste artigo, discutimos como a Análise da Conversa, também conhecida como Análise da Fala-em-Interação, abordagem teórico-metodológica de cunho qualitativo, pode contribuir para que ambos os enfoques sejam contemplados nas pesquisas sobre desenvolvimento infantil e significados socioculturais acerca de infância.

* Endereço para correspondência: Universidade do Vale do Rio dos Sinos, Centro de Ciências da Comunicação, Avenida Unisinos, 950, Cristo Rei, São Leopoldo, RS, Brasil, CEP 93022-000.E-mail: schnack@unisinos.br
Borges e Salomão (2003) discutem a importância da interação social no processo de aquisição da linguagem, argumentando pelo não dualismo natureza-ambiente como fatores mutuamente excludentes nesse processo. As autoras também discorrem sobre as possibilidades de posicionamento do sujeito que a interação verbal acaba por instaurar para crianças e adultos, posicionamentos esses que podem ser de alguém que faz um convite a outra pessoa, dá uma ordem, responde (assentindo ou não) a esta ordem, entre outros. As diversas possibilidades de posicionamento caracterizam-se como momentos de pleno desenvolvimento linguístico-cognitivo. As autoras consolidam um campo fértil de pesquisas que não necessita recorrer à criação de ambientes que reproduzam o contexto no qual as crianças vivem para fomentar um estudo, mas que investiga o que de mais corriqueiro e trivial as crianças realizam: seu engajamento em interações face-a-face com seus pais e mães.

Borges e Salomão (2003) acabam por oportunizar a reflexão sobre um aspecto não necessariamente central 
em seu artigo, que diz respeito à relevância cultural desse processo de aquisição. Já no início do texto, os autores colocam que "a linguagem é a primeira forma de socialização da criança" (p. 327), processo que Ochs e Schieffelin (1986) nomeiam como socialização da linguagem, entendendo que esse processo também socializa a criança através do uso da linguagem. Socializar-se significa, a partir de então, compartilhar códigos, significações e práticas locais e, a partir daí, fazer parte de determinada comunidade.

Assim, não apenas o aspecto social da socialização da linguagem e do desenvolvimento infantil deve ser levado em conta, mas também sua significação cultural. Por social, assumimos, entre outros, o aspecto da presença do outro, a pressuposta intercalação de turnos de fala, e a maneira como os interlocutores organizam suas falas. Ao assumirmos que toda interação social é cultural, vinculamos esta organização social a significados locais, a processos de significação de determinadas práticas em comunidades específicas, e entendemos infância como culturalmente relevante. Em outras palavras, infância não é concebida aqui como uma categoria com significados universais; sua significação é negociada e ratificada na fluidez interacional na qual crianças e adultos se engajam e onde o desenvolvimento se dá.

Passamos, a partir daqui, a utilizar o termo "socialização da linguagem" por entendermos que ele contempla a busca pelo entendimento de como as pessoas se tornam membras de um grupo social através do uso da linguagem e de como a aquisição de formas de uso da linguagem se constitui parte do processo de adquirir competência social (Schieffelin \& Ochs, 1986). Além disso, Borges e Salomão (2003), conforme mencionado anteriormente, também assumem o aspecto de socialização que o uso da linguagem acarreta.

Um dos construtos clássicos da literatura sobre desenvolvimento infantil, o uso de baby talk, é então redimensionado e passa a ser compreendido como uma das práticas de determinados grupos sociais (Ochs \& Schieffelin, 2001). O que Ochs e Schieffelin (2001) revelam são os significados culturais distintos acerca de infância que os diversos modos de interagir com as crianças (com ou sem uso de baby talk) acabam por configurar. Esse redimensionamento envolve dois construtos relevantes: (a) a noção de comunidade e (b) a noção de participação.

Lave e Wenger (1991) tomam "comunidade" como uma "comunidade de prática", que está organizada em torno das práticas compartilhadas de seus participantes. Nessa concepção, entende-se que tornar-se membro exige participar da comunidade. Para M. Goodwin (2001), a organização da participação pode ser analisada a partir dos posicionamentos dos interagentes a cada nova ação realizada na interação, o que também revela as formas de envolvimento dos participantes ao longo da trajetória interacional.

É justamente na convergência dos entendimentos acerca de "comunidades de prática" e de "participação" que estudos da Psicologia, como o de Rogoff (2003), alicerçam sua pesquisa para dar conta do aspecto cultural que delineia o processo de desenvolvimento infantil - e do ser humano como um todo. O que tanto Ochs e Schieffelin (2001) quanto Rogoff (2003) estão interessadas em conhecer são as práticas desempenhadas pelos membros de cada grupo estudado de forma a compreender o que constitui cada grupo e, a partir daí, acessar o processo de desenvolvimento das crianças.

É nesse contexto de discussão que o presente estudo se insere. Objetiva-se contribuir com a literatura sobre desenvolvimento infantil e significação de infância/s ao propor a análise das práticas locais a partir de uma abordagem qualitativa de cunho etnográfico que possibilita o detalhamento minucioso das interações verbais nas quais membros de duas famílias se engajam rotineiramente.

\section{Método}

\section{Introduzindo a Análise da Conversa aos Estudos em Psicologia no Brasil}

Caracterizar a trajetória de participação nas práticas locais demanda uma perspectiva teórico-analítica qualitativa (e.g. Duranti, 1997; Geertz, 1998) que dê conta das complexidades envolvidas em tais práticas. Dessa forma, utilizamos a abordagem metodológica da Análise da Conversa (Sacks, 2002), abordagem esta também conhecida como Análise da Fala-em-Interação. Conforme explicam Ostermann e Souza (2009), essa perspectiva caracteriza-se por buscar compreender os métodos utilizados pelos próprios atores sociais enquanto desempenham diferentes papéis (como, por exemplo, de cuidador, de pai, de mãe, de filho, de adulto e de criança).

A Análise da Conversa (doravante, também AC) tem sido largamente utilizada, principalmente nos Estados Unidos, Grã-Bretanha e Finlândia, não apenas em estudos de socialização da linguagem como o aqui proposto (e retomado a seguir), mas também em estudos de cunho qualitativo que investigam a construção da realidade, do conhecimento e de identidades sociais através das interações. Destacamos aqui os estudos de interação em consultas psicoterapêuticas (Forrester, 1999; Gale, 1991), em consultas médicas em geral (Barnes, 2005; Drew, Chatwin, \& Collins, 2001; Ostermann \& Souza, 2009), no sistema legal (Heydon, 2005) e no sistema educacional (Erickson, 1996).

Uma importante assunção para a AC é que as interações no mundo são um fato social. Estudos desenvolvidos a partir dessa perspectiva metodológica tratam da fala como uma forma de ação social, ou seja, como uma forma de fazer coisas no mundo (mandar, exigir, obedecer, discordar, fazer infância). Dessa forma, a AC investiga como as pessoas envolvidas em uma interação compreendem o que sua fala e a fala de seus interagentes estão "fazendo." Daí a necessidade de estudar a fala nas práticas sociais. Considerando-se o estudo aqui apresentado, olhamos para o "fazer" socialização que pode, como já mencionado, ser tanto das práticas sociais através da lin- 
guagem como do uso da linguagem em si e seus significados sociais. Contudo, para fins de recorte analítico, voltamos nosso olhar, aqui, para a socialização das práticas sociais enquanto ações sociais significadas culturalmente.

Nesse sentido, e em consonância com os pressupostos teórico-metodológicos da Análise da Conversa, não partimos de um conceito apriorístico de infância, mas buscamos nas práticas interacionais das famílias investigadas a emergência e constituição da significação de infância em cada família. Sendo assim, em conformidade com essa perspectiva teórico-analítica, os dados utilizados para esta pesquisa são naturalísticos, ou seja, são analisadas as interações que ocorreram (e que ocorreriam) no dia a dia dos participantes sem a intervenção das pesquisadoras e no ambiente natural de sua ocorrência. Da mesma forma, o foco analítico é data-driven, ou seja, determinado a partir de fenômenos que são, de várias maneiras, evidenciados nos dados da interação.

Além disso, conforme explica Ostermann (2005), diferentemente de pesquisas que se centram no conteúdo das falas ou apenas no que foi dito, estudos de AC focalizam primordialmente o como as coisas foram ditas (pausas, falas coconstruídas, falas simultâneas, hesitações e outros fenômenos interacionais). Cameron (2001) compara a análise da $\mathrm{AC}$ a um microscópio, que possibilita que vejamos "o que normalmente tomamos como dado" (p. 89) e que revela o quão complexas - e organizadas - são nossas interações verbais cotidianas. Como não poderia ser diferente, estudos desenvolvidos a partir dessa perspectiva pressupõem que a coleta de dados seja feita através de vídeo e/ou áudio.

\section{Coleta de Dados e Participantes}

Tendo em vista o pressuposto teórico-analítico empregado neste estudo, a coleta de dados deu-se de maneira a capturar o universo doméstico-familiar das duas famílias estudadas. Dois critérios principais foram utilizados para a seleção das famílias: (a) que existisse uma criança de três anos na família, considerando três anos uma idade em que a fala das crianças é compreensível a terceiros e (b) que as duas famílias representassem diferentes camadas sociais. Em função da natureza dos dados que se almejava, ou seja, de dados naturalísticos registrados em áudio e vídeo durante interações no ambiente íntimo de um lar, as duas famílias selecionadas foram aquelas que nos permitiram esse tipo de acesso - famílias essas que foram contatadas por meio de redes de contatos pessoais e profissionais.

Denominamos, ao longo da discussão que segue, uma família como Família de Paulo e a outra como Família de Catarina (sendo que Paulo e Catarina são as crianças de três anos), ressaltando que todos os nomes são fictícios de forma a salvaguardar as identidades das pessoas envolvidas. Cabe destacar aqui que a pesquisa seguiu os preceitos éticos que regem a pesquisa científica que envolve seres humanos (com uso de Termos de Consenti- mento Livre e Esclarecido), obtendo a homologação 06/ 2006 pelo Comitê de Ética em Pesquisa da Unisinos.

Foram empregados basicamente três instrumentos de coleta dos dados, quais sejam: (a) entrevistas semi-estruturadas, que foram essenciais para a aproximação com o universo de cada família estudada; (b) filmagem das interações familiares ao longo de dez dias consecutivos, realizada pelas próprias famílias em momentos distintos de seu convívio cotidiano (cada família pode escolher os momentos diários a serem filmados, embora as duas famílias tenham sido incentivadas a filmar momentos distintos de sua rotina, de forma a capturar uma variedade maior de rituais familiares). Essas filmagens renderam, na família de Catarina, em torno de dez horas de filmagem, e na família de Paulo, em torno de cinco horas; (c) convivência da primeira autora com cada família, em seus lares, ao longo de três semanas, com duas ou três visitas semanais, de acordo com a disponibilidade de cada família em cada semana.

Os dados advindos de cada instrumento de coleta nos permitiram retratar qualitativamente as práticas que caracterizam cada família e, desse modo, lançar nosso olhar sobre os significados situados dessas práticas. As entrevistas semi-estruturadas serviram, em um primeiro momento, como a ferramenta através da qual as pesquisadoras puderam fazer as primeiras inferências sobre como as práticas locais estavam organizadas. A análise das interações filmadas e gravadas foram confrontadas com os dados gerados a partir dessa primeira aproximação (feita através das entrevistas semi-estruturadas). $\mathrm{O}$ terceiro momento, o de convívio da primeira pesquisadora com as famílias estudadas, foi importante para que os momentos que se mostravam singulares nas filmagens pudessem ser significados.

As interações filmadas pelas famílias foram transcritas de maneira a cristalizar os momentos interacionais, efêmeros por natureza. As transcrições utilizadas são adaptações daquelas criadas por Gail Jefferson (Atkinson \& Heritage, 1984). Uma versão traduzida para o português e adaptada para fins específicos encontra-se em Schnack, Pisoni e Ostermann (2005) e está reproduzida aqui como Anexo.

Sobre as famílias participantes:

A Família de Paulo. A família de Paulo é constituída por sua mãe, Leila, e seu pai, Ângelo. Leila é fonoaudióloga e trabalha um turno em uma empresa que presta serviços sociais à comunidade. Ângelo ocupa um cargo de superintendência de uma empresa. Paulo estuda em uma escola de educação infantil no turno da manhã e, pela tarde, volta com a mãe para casa, ou realiza com ela outras atividades, como ir ao centro de compras, por exemplo.

Ao final do dia, organizam suas atividades de forma a promover o compartilhamento de experiências vividas e de planos para o futuro. As experiências de Paulo, tanto aquelas vivenciadas na escola quanto aquelas vivenciadas 
em companhia da mãe, recebem destaque nesses momentos de compartilhamento de experiências. Além disso, as atividades em que se engajam não são, em essência, atividades individuais; normalmente buscam a parceria do outro para sua realização: olhar televisão, por exemplo, torna-se uma atividade em que Paulo e Ângelo com frequência se engajam juntos, e em geral o programa assistido é de interesse de Paulo e escolhido por ele.

A Família de Catarina. A família de Catarina é composta por seu pai, Valmor, sua mãe, Carmen, e seu irmão, Washington, que tinha 11 anos à época da coleta de dados. Em termos profissionais, Valmor realiza trabalhos temporários de naturezas distintas, como construções e reformas residenciais, consertos domésticos e serviços de jardinagem, por exemplo. Alterna dias de muita atividade com dias com menos serviço. Carmen mantém um emprego com carteira assinada em uma lancheria no centro da cidade em que a família mora. Washington estuda no turno da manhã e passa as tardes em casa, na casa de amigos ou na rua em frente a sua casa, sendo ele próprio o responsável pela organização de seu dia. Catarina é cuidada por uma mulher chamada pelos participantes de Vó Nina, que cuida também de outras crianças - todas mais velhas que Catarina.

Ao final do dia, todos se encontram novamente reunidos em casa, engajados em tarefas distintas, mas compartilhando o restrito espaço físico que configura a casa. Catarina empenha-se em ter a atenção da mãe para brincar, contar histórias ou mesmo cantar em frente ao DVDKaraokê. Carmen e Valmor, por outro lado, dividem-se entre as tarefas domésticas como, lavar e passar roupa, arrumar a casa, fazer a janta, entre outras, além de descansar do dia de trabalho que tiveram. A disputa pela televisão é sempre a mais acirrada, especialmente entre Catarina e Carmen.

\section{Análise dos Dados e Discussão}

Analisamos aqui dois excertos de interações com as crianças de três anos nas duas famílias pesquisadas. Ainda que, por questões de limitação de espaço, discutamos apenas um excerto de cada família, cabe registrar que esses excertos foram selecionados justamente pela sua representatividade de inúmeros outros momentos evidenciados na análise do largo universo de dados coletados durante a pesquisa, seja em gravações em áudio e vídeo, seja através das observações presenciais. Sendo assim, o que podem parecer exemplos isolados são, ao contrário, extremamente representativos das situações cotidianas evidenciadas de forma recorrente em cada uma das famílias pesquisadas. O critério "recorrência" (e, por meio dele, de representatividade), assim como em outras abordagens metodológicas de cunho qualitativo, caracterizase como o principal critério de seleção desses excertos em particular. Finalmente, cabe também informar que, como a Análise da Conversa se propõe a analisar momentos de fala-em-interação de forma micro e extremamente minuciosa, torna-se praticamente inviável discutir em um artigo todas as interações gravadas e analisadas. Iniciemos, então, pela análise de uma interação na família de Paulo.

\section{Uma Interação na Família de Paulo}

$\mathrm{Na}$ interação analisada a seguir (Excerto 1), temos Paulo e Ângelo engajados em uma atividade na sala de estar, e Leila na cozinha, realizando outra tarefa. Sala e cozinha são ambientes distintos de um mesmo (amplo) cômodo. No mesmo andar da casa ainda há uma lavanderia e um lavabo. Os demais cômodos (quartos e banheiros) localizam-se no andar superior da casa.

Excerto 1: [Paulo; 01/02; 32min06]
368 Ângelo:
369
que que eles tão fazendo? (.) (h)m?
370 Leila:
(.)
371
que que eles tão fazendo paulo? ((Leila está em outro ambiente,
372 Paulo: provavelmente na cozinha, pela distância da voz.))
373 Ângelo:
nada.
374
eles não tão fazendo na::da?
375
((Ângelo e Paulo estão sentados no sofá - Paulo no colo
376
de Ângelo - assistindo televisão juntos. O foco do olhar de
377
378 Ângelo:
ambos é a televisão. O telefone toca e Ângelo até move um
pouco seu corpo, mas não levanta para atendê-lo. Leila atende.))
379 Leila:
quem será::?
380 Ângelo:
((ao telefone, com a voz distante) $)^{\circ}$ quem? (.) oi cícero. (h)a tá. só um pouquinho. ${ }^{\circ}$
381 Leila:
só um pouquinho. ((tira Paulo de seu colo)) deixa o pai falá com o cícero.
382
${ }^{\circ}$ vem aqui. ${ }^{\circ}$ ((Paulo sai do enquadre e vai novamente em direção
383 Ângelo: à poltrona onde estava sentado antes.))
cícero? tudo bem:? e aí?

Nos minutos que precedem esse excerto, Ângelo e Paulo haviam iniciado a atividade de assistir um desenho animado veiculado em um canal de televisão pago voltado para o público infanto-juvenil e cujo gênero televisivo principal é de desenhos animados. Embora tanto Paulo quanto Ângelo possuam capacidades visuais e auditivas 
que permitem que ambos compreendam o que se passa no desenho animado, Ângelo engaja Paulo em uma atividade de (re)construir a narrativa da história. Nesse sentido, Ângelo questiona Paulo sobre o que está acontecendo na história. Entre as linhas 368 e 373 pode-se observar como isto ocorre: Ângelo elabora perguntas a Paulo sobre as ações dos personagens. Embora a atividade seja entre Paulo e Ângelo, Leila, na linha 370, toma o turno de fala e reelabora a pergunta de Ângelo após um silêncio que seria, a princípio, de responsabilidade de Paulo, uma vez que o menino era o endereçado da pergunta do pai. O menino, ao não tomar o turno de fala, cria um espaço interacional para que Leila se alinhe a Ângelo em fazer Paulo participar da atividade. Nesse momento, Leila explicitamente endereça seu turno de fala a Paulo, usando o vocativo "Paulo" (“que que eles tão fazendo Paulo?").

Interessante observar que Leila, embora não estando diretamente focalizada na atividade na qual Ângelo e Paulo estão engajados, participa dela remotamente e, ao fazê-lo, alinha-se ao papel que Ângelo desempenha na interação, isto é, o de ser interlocutora de Paulo, fazendo com que ele (re)construa a narrativa do desenho animado. A Paulo é ofertado amplo espaço interacional, tanto de seu pai quanto de sua mãe, para que se posicione sobre as coisas no mundo; neste caso, o mundo televisivo.

Na sequência, Paulo de fato toma o turno de fala e responde à pergunta de Leila, reelaborada a partir da pergunta de Ângelo. A resposta de Paulo, na linha 372, contudo, é uma resposta que não atende às expectativas de Ângelo, especialmente pelo fato de que o próprio Ângelo percebe que os personagens estão realizando algo. $\mathrm{Na}$ linha 373, Ângelo desafia a resposta que Paulo fornecera ao repetir a resposta do menino em tom ascendente, oportunizando, uma vez mais, um momento para o menino elaborar seu pensamento e se posicionar ("eles não tão fazendo na::da?").

Embora não se tenha a resposta do menino na sequência, é justamente o fato de uma atividade distinta daquela em que ambos estavam engajados ser inserida no transcorrer do tempo que se torna interessante. Ângelo não mais insiste na resposta do menino, respeitando sua quase resistência em se engajar na atividade que o pai propunha. Ângelo, contudo, ainda orientado para o fato de que ele e o menino estão mutuamente engajados e focados em uma mesma atividade, acaba por elaborar uma pergunta que está orientada ao fato de o telefone ter tocado: Ângelo parece novamente estar engajando Paulo em uma atividade conjunta, ou seja, determinar quem está ao te- lefone. Na linha 382, Ângelo retira-se da atividade de assistir televisão em função de um chamado "externo" a ligação do telefone destina-se a Ângelo. Ao se retirar, Ângelo orienta-se para o fato de que ele e Paulo têm um compromisso mútuo, em função de uma atividade conjunta em curso. Sendo assim, Ângelo produz uma justificativa para o fato de se ausentar da atividade de assistir televisão, ao dizer "deixa o pai falá com o cícero" (linha 380). Além disso, torna-se interessante observar que, nesse momento, é Leila quem busca a orientação de Paulo, tornando-o seu interlocutor. É como se Leila desempenhasse o papel que Ângelo desempenhara até aquele momento, o de interagir com Paulo, de fazê-lo engajarse em uma interação que está especialmente construída em torno dos assuntos que interessam ao menino.

Ao organizarem suas participações na atividade de assistir televisão, Ângelo, Paulo e Leila estão construindo seu entendimento do que sejam os momentos familiares e o que seja o espaço de participação da criança (e do/a adulto/a) nesse ambiente doméstico-familiar. Ângelo e Leila constroem-se como os responsáveis por criar momentos cujo centro de atenção seja Paulo e cujos tópicos girem em torno dos interesses do menino. São os adultos que se inserem no mundo da criança e, dessa maneira, criam um espaço privilegiado para ela. Sobre a criança recai a expectativa de engajar-se nessas interações. Nem mesmo um chamado externo faz com que Paulo seja relegado a uma posição interacional mais periférica nas interações nessa família. Ou seja, ao retirar-se da interação, Ângelo justifica-se a Paulo, e Leila abandona a atividade na qual estava engajada na cozinha para dar continuidade à construção desse espaço privilegiado que Paulo detém na família.

\section{Uma Interação na Família de Catarina}

O excerto de interação que analisamos a seguir (excerto 2) advém da família de Catarina, mais especificamente, de um momento em que Catarina, Valmor e Carmen estão em casa após um dia de trabalho. A casa possui dois cômodos divididos em quatro ambientes - sala e cozinha, quarto do casal e quarto das crianças - mais um banheiro. Carmen e Catarina estão sentadas no sofá da sala, e Valmor caminha pela casa. Carmen está, na verdade, sentada na borda do sofá, de forma que seu corpo parece estar nos limites entre estar sentada e estar levantando-se. Catarina, por outro lado, está plenamente acomodada sobre o sofá. Ambas engajam-se em uma atividade em que Catarina lê uma história para sua mãe.

Excerto 2: [Catarina; 01/2005; 1h39']

$\begin{array}{ll}158 \text { Carmen: } & \text { vai lá. lê e::sse. } \\ 159 \text { Cata: } & \text { e::sse? } \\ 160 \text { Carmen: } & \text { é. esse. } \\ 161 \text { Valmor: } & \text { bah::, falá nisso deixei as pipoca no microondas. ((Carmen olha para Valmor } \\ 162 & \text { quando ele inicia seu turno de fala.)) } \\ 163 & \text { ((Catarina volta a olhar seus livros - sozinha. Carmen está }\end{array}$


164

165 Cata:

166 Carmen:

167 Valmor:

168 Carmen:

169 Cata:

170 Valmor:

171 Cata:

172 Carmen:

173 Cata:

174

175 Carmen:

176 Cata:

177 sentada na ponta do sofá olhando para Valmor.))

e::sse ((Fala enquanto pega mais um livro na mão.))

é? ((Continua olhando para Valmor.))

deixei as pipoca dentro [XXX

[mas tá fechado?

oh mãe::: ((Bate na perna de Carmen enquanto fala.))

tá, mas tinha começado a estourá (elas).

é ma-

ah:::.

é mamão?

(.)

mamão. ((Volta-se para Catarina para responder a pergunta.))

ma- mão. (.) o mamão e a mulher dele. XX. a::gora, (.) que eles ficaram (.) muito

feliz por causa que eles (iam para uma floresta). numa floresta muito lin::da.
A atividade, que já havia sido iniciada anteriormente, interrompida e reiniciada outras vezes, é retomada por Carmen nesse momento. Na linha 158, percebe-se Carmen elaborando um diretivo, tomado aqui como forma de fazer com que outros façam alguma coisa solicitada, bastante imperativo para Catarina, definindo qual livro ela deveria ler ("vai lá. lê e::sse"), já que a menina tinha outros livros em suas mãos. Catarina, contudo, mostra dificuldade em identificar o referente do pronome "esse" empregado pela mãe: deveria ser o livro que Carmen acabara de colocar sobre o sofá ou aquele que tinha em suas mãos, e que as duas estavam juntando do chão? Na linha 160, Carmen resolve a questão ao confirmar à Catarina o livro que ela deveria ler, sem mais explicações. Nesse momento, Valmor volta-se para Carmen e dá prosseguimento a uma atividade na qual ambos estavam engajados anteriormente: compartilhar a identificação do problema que ocorrera com o forno de microondas e que fora solucionado por Valmor. Valmor expande o assunto de sua interação com Carmen ao realizar a descrição de suas ações com relação ao microondas, nas linhas 161-162. Interessante observar que embora Valmor não tenha selecionado explicitamente sua interlocutora pelo uso de um vocativo, por exemplo, Carmen não mostra ter dificuldades em se auto-selecionar como tal, pois já no início de seu turno volta seu olhar a Valmor. O direcionamento de olhar para aquela pessoa que fala mostra engajamento com essa fala (C. Goodwin, 1986). Por outro lado, ao abster-se de voltar seu olhar para Catarina, Carmen dá pistas de que a atividade em que está engajada com a filha constitui um segundo plano, e não a atividade principal com a qual se encontra comprometida.

Na linha 166, Carmen continua orientada para Valmor, avaliando as ações que ele acabara de descrever. Ao fazê-lo, Carmen dá pistas a Valmor de que ele pode prosseguir com sua narrativa, demonstrando total comprometimento com esta atividade.

Ao que segue, fica sob a responsabilidade de Catarina interpelar por atenção da mãe, realizando um chamamento explícito e agravado, já que a menina elabora um vocativo produzido de forma alongada e prefaciado por uma interjeição (“oh, mãe:::", na linha 169). O agravamento da ação de Catarina está configurado pelo fato de Catarina bater na perna de Carmen ao longo de seu turno de fala. É somente na linha 175 que Carmen volta à atividade com Catarina, oportunizando a continuação da narrativa por parte da menina. Carmen orienta-se à pergunta que a menina iniciara na linha 171, quando é interrompida pela fala da mãe, e que finalizara na linha 173. A partir daí, Catarina parece estar ratificada por sua interlocutora (a mãe) a dar prosseguimento na leitura da história, conforme a própria mãe havia lhe solicitado no início da atividade, que não consta deste excerto.

A partir deste excerto, que representa outros tantos similares nesta família, podemos ter acesso à concepção de participação nesta família e aos direitos e deveres envolvidos nas relações. Um dos aspectos que se mostra relevante para reflexão a partir desse excerto é a configuração do que significa infância para esta família, em especial no que tange à questão do "lugar" da criança na família. A partir da análise dessa interação, é possível inferirmos que em primeiro plano estão as interações adulto-adulto, com suas questões "de vida prática" para serem resolvidas. Neste caso em específico, o conserto do microondas torna-se mais relevante do que a oportunidade de Catarina ter um momento lúdico propiciado por sua mãe. Apesar de ter sido Carmen quem propusera a atividade para a filha, ela não demonstra ter dificuldades em "abster-se" desse compromisso firmado com a menina. Veladamente, Carmen mostra à menina que a atividade que ela propusera deve ser compreendida como uma atividade que pertence ao mundo da menina (e não necessariamente ao mundo dos adultos) e que pode perfeitamente ser realizada individualmente por ela, a menina.

\section{Considerações Finais}

Nesse estudo, buscamos mostrar como podemos verificar em interações naturalísticas e utilizando abordagem metodológica da Analise da Conversa a organização da participação em interações face-a-face que ocorrem cotidianamente entre crianças e adultos. Ao 
estudarmos as interações face a face, podemos acessar a participação das pessoas nas atividades socioculturais nas quais se engajam. Ou seja, a descrição minuciosa, turno a turno, das práticas interacionais nas quais adultos e crianças se engajam se mostra extremamente produtiva na medida em que possibilita que se estabeleçam relações entre a organização social dessas práticas e a significação cultural que é parte constitutiva dessa organização.

Se é certo que a participação nas comunidades de prática (Lave \& Wenger, 1991; Rogoff, 2003; Wenger, 1998) das quais fazemos parte faz com que construamos as cognições sociais que definem tais comunidades (Rogoff, 2003), poderemos acessar o que cada família concebe como "infância", por exemplo. A obra de Ariès (1981), que instaura o olhar histórico acerca da infância nas pesquisas sociais, é discutida justamente neste ponto: que infância é aquela que o autor tão magistralmente descreve, ou sobre cuja trajetória evolucionista escreve? Embora não seja possível descolar o significado de infância de seu momento histórico, parece ser importante também discuti-lo à luz de aspectos socioculturais, como descrito aqui e em estudos anteriores. Compreende-se, aqui, que o contexto histórico é constitutivo das práticas socioculturais.

A partir de Rogoff (2003), podemos depreender que as competências, as características e as expectativas que circundam a infância são culturalmente definidas através das práticas significadas por cada comunidade de prática. Nas famílias de Paulo e Catarina, por exemplo, podemos pensar a significação de infância de formas bastante distintas. Para Paulo são ofertados, pelo adulto, na maneira como lhe são endereçados turnos de fala, momentos de se posicionar e de elaborar seu pensamento. Já de Catarina, parece ser esperado que a menina perceba os momentos de interação entre adultos como eventos em primeiro plano, e que os respeite como tal. Posicionar-se e elaborar seu pensamento são oportunidades a serem conquistadas pela menina.

De certa forma semelhante ao que vemos descrito por Ochs (1982) sobre as famílias samoanas, na família de Catarina, infância parece mostrar-se como um espaço de crescimento, da criança tornar-se adulta para só então poder participar - legitimamente - das interações com os demais (adultos). A infância, naquela família é, pois, uma fase de transição. Carmen e Valmor não se mostram orientados a se inserir no mundo de Catarina - embora a mãe tenha dado uma pista de que faria isso, ao convidar Catarina para ler um livro para ela. Cabe reportar que, apesar de não trazidas aqui, há várias interações na família de Catarina em que seu irmão mais velho, diferentemente de Catarina, é tomado como participante legítimo das interações com os pais, sendo suas falas sempre ratificadas.

Na família de Paulo, por outro lado, Ângelo e Leila estão, a todo o momento, mostrando-se orientados para infância como um espaço de franca atividade, de estímulo da criança pelos adultos - nesse caso, os pais. Infância parece mesmo constituir-se um espaço legítimo em si, um espaço de desenvolver-se enquanto criança - sem perder vistas ao mundo adulto lá fora. As atividades dos adultos estão organizadas em função das necessidades e interesses dessa criança, que pode ou não desfrutar desses momentos oportunizados pelos adultos. Lareau (2003) chama essa prática de concerted cultivation, que poderia ser compreendida como "desenvolvimento orquestrado".

Com isto, não estamos fazendo nenhum movimento para identificar a melhor concepção de infância, até porque essas concepções estão intimamente vinculadas às necessidades e às perspectivas sociais de cada grupo estudado e também porque, como menciona Erickson (2004), toda a situação social tanto abre possibilidades quanto impõe restrições. Se pensarmos em Catarina, a menina mostra-se competentemente batalhando para ser ratificada como participante daquela interação - o que, ao fim e ao cabo, consegue. Além disso, não apenas o universo infantil está à disposição do escrutínio de Catarina. Também um vasto universo adulto, com suas práticas e conhecimentos valorados, está ao seu alcance.

Paulo, embora seja amplamente estimulado a participar, não parece ser estimulado a "fazer-se ouvir" por outras pessoas, tarefa interacional essa mais árdua. As interações das quais participa, embora ocorram entre três pessoas, mostram-se estruturalmente diádicas na medida em que seu pai e sua mãe acabam por desempenhar o papel de um "time" (Goffman, 1959) que tem o mesmo objetivo, ou seja, o de um por vez apresentar-se como interlocutor de e somente de Paulo. Como no mundo para além daquela esfera familiar, interações multipartidárias e multifacetadas mostram-se a maioria, poderemos refletir sobre a não socialização, no ambiente doméstico-familiar, nessas práticas, o que poderia até mesmo representar perdas para Paulo.

Sendo assim, também pode ser produtivo pensar que as concepções acerca de infância estão intimamente vinculadas a um processo mais amplo de constituição e significação, pelas práticas locais, dos segmentos sociais dos quais as famílias fazem parte, questão essa que é discutida mais amplamente em Schnack (2006). Conforme discute Rogoff (2003), é a partir da participação nessas práticas que crianças e adultos têm seu processo de desenvolvimento como um todo tornado possível.

Alguns estudos têm buscado vincular essas primeiras práticas nas quais as crianças são socializadas com as outras práticas nas quais as crianças serão (possivelmente) socializadas, pensando sobre como elas poderiam estar interrelacionadas. Heath (1986), por exemplo, analisa a relação entre práticas familiares de contação de história e desenvolvimento escolar, ao passo que Lareau (2003) discute práticas familiares enquanto possibilidades de diferentes atuações das crianças em contextos que não o 
contexto familiar. O que ambos os estudos ressaltam não está vinculado a um fazer melhor do que o outro, mas às possibilidades de significação de mundo e de desenvolvimento infantil que cada processo de socialização contempla.

Sendo assim, a contribuição desse estudo reside em dois aspectos principais. O primeiro é a discussão de uma abordagem teórico-metodológica que possibilite a análise da relação entre desenvolvimento infantil e construção dos significados acerca da infância explorando o que de mais mundano as pessoas fazem: interagir em suas famílias. O segundo é a proposição de análise de dados naturalísticos de famílias brasileiras, o que, por consequência, traz ao corpo de estudos dessa natureza já em andamento em outros países a compreensão de como esses processos primordiais na vida de todas as pessoas ocorrem em lares brasileiros. Neste sentido, o estudo também contribui para que o campo de investigação aqui apresentado consolide-se no Brasil.

\section{Referências}

Ariès, P. (1981). História social da criança e da família $\left(2^{\text {nd }}\right.$ ed.). Paris: Editions du Seuil.

Atkinson, M., \& Heritage, J. (Eds.). (1984). Structures of social action. Cambridge, MA: Cambridge University Press.

Barnes, R. (2005). Conversation analysis: A practical resource in the health care setting. Medical Education, 39, 113-115.

Borges, L. C., \& Salomão, N. M. R. (2003). Aquisição da linguagem: Considerações da perspectiva da interação social. Psicologia: Reflexão e Crítica, 16(2), 327-336.

Braz, F. S., \& Salomão, N. M. R. (2002). A fala dirigida a meninos e meninas: Um estudo sobre o Input materno e suas variações. Psicologia: Reflexão e Crítica, 15(2), 333-344.

Cameron, D. (2001). Working with spoken discourse. London: Sage.

Drew, P., Chatwin, J., \& Collins, S. (2001). Conversation analysis: A method for research into interactions between patients and health-care professionals. Health Expectations, 4, 58-70.

Duranti, A. (1997). Linguistic Anthropology. Cambridge, MA: Cambridge University Press.

Erickson, F. (1996). Going for the zone: The social and cognitive ecology of teacher-student interaction in classroom conversations. In D. Hicks (Ed.), Discourse, learning, and schooling (pp. 29-62). Cambridge, MA: Cambridge University Press.

Erickson, F. (2004). Talk and social theory: Ecologies of speaking and listening in everyday life. Cambridge, MA: Polity Press.

Ervin-Tripp, S. (1979). Children's verbal turn-taking. In E. Ochs \& B. Schieffelin (Eds.), Developmental pragmatics (pp. 391-414). New York: Academic Press.

Forrester, M. A. (1999). Conversation analysis: A reflexive methodology for Critical Psychology. Annual Review of Psychology, 1, 34-49.

Gale, J. E. (1991). Conversation analysis of therapeutic discourse: The pursuit of a therapeutic agenda (Vol. XLI). Norwood, NJ: Ablex.

Geertz, C. (1998). O saber local: Novos ensaios em antropologia interpretativa. Rio de Janeiro, RJ: Vozes.
Goffman, E. (1959). The presentation of the self in everyday life. New York: Anchor Books.

Goodwin, C. (1986). Audience diversity, participation and interpretation. Text, 6(3), 283-316.

Goodwin, M. (2001) Participation. In A. Duranti (Ed.), Key terms in language and culture (pp. 172-175). Malden, MA: Blackwell.

Goodwin, M. (2007). Occasioned knowledge exploration in family interaction. Discourse and Society, 18, 93-110.

Heath, S. (1986). What no bedtime stories means: Narrative skills at home and school. In B. Schieffelin \& E. Ochs (Eds.), Language socialization across cultures (pp. 97-124). Cambridge, MA: Cambridge University Press.

Heydon, G. (2005). The language of police interviewing: A critical analysis. Houndmills, UK: Palgrave MacMillan.

Lareau, A. (2003). Unequal childhoods: Class, race, and family life. San Diego: University of California Press.

Lave, J., \& Wenger, E. (1991). Situated learning: Legitimate peripheral participation. Cambridge, MA: Cambridge University Press.

Ochs, E. (1982). Talking to children in Western Samoa. Language in Society, 2, 77-104.

Ochs, E., \& Schieffelin, B. (1986). Language socialization across cultures. Cambridge, MA: Cambridge University Press.

Ochs, E., \& Schieffelin, B. (2001). Language acquistion and socialization: Three developmental stories and their implications. In A. Duranti (Ed.), Linguistic Anthropology: $A$ reader (pp. 263-301). Oxford, UK: Blackwell.

Ostermann, A. C. (2005). Gênero, sexualidade e violência: Uma investigação sociolingüística interacional de atendimentos à saúde da mulher. Projeto de Pesquisa não-publicado, Universidade do Vale do Rio dos Sinos, São Leopoldo, RS.

Ostermann, A. C., \& Souza, J. (2009). Contribuições da análise da conversa para os estudos sobre o cuidado em saúde: Reflexões a partir das atribuições feitas por pacientes. $\mathrm{Ca}$ dernos de Saúde Pública (FIOCRUZ), 25(7), 105-117.

Rogoff, B. (2003). The cultural nature of human development. Oxford, UK: Oxford University Press.

Sacks, H. (2002). Lectures on conversation (Vols. 1-2). Oxford, UK: Blackwell.

Schieffelin, B., \& Ochs, E. (1986). Language socialization. Annual Review of Anthropology, 15, 163-191.

Schnack, C. M. (2006). Do ser ao fazer: Infância e família na perspectiva da socialização da linguagem. Dissertação de Mestrado não-publicada, Universidade do Vale do Rio dos Sinos, São Leopoldo, RS.

Schnack, C. M., Pisoni, T. D., \& Ostermann, A. C. (2005). Transcrição de fala: Do evento real à representação escrita. Entrelinhas, 2(2). Retrieved November 24, 2006 from http:/ /www.entrelinhas.unisinos.br/index.php? $=2 \& \mathrm{~s}=9 \& \mathrm{a}=12$

Snow, C., \& Ferguson, C. (Eds.). (1977). Talking to children: Language input and acquisition. Cambridge, MA: Cambridge University Press.

Wenger, E. (1998). Communities of practice: Learning, meaning and identity. Cambridge, MA: Cambridge University Press. 


\section{Anexo}

\section{Convenções de Transcrição}

[texto] Colchete esquerdo indica o início da sobreposição de vozes. Colchete direito indica o final.

(.) Representa a ausência de fala ou vocalização.

, Indica entonação contínua, como ao listar itens.

- $\quad$ Indica entonação descendente e final.

? Indica entonação ascendente.

- $\quad$ Interrupção abrupta da fala em curso.

: $\quad$ Indica alongamento de vogal ou consoante.

${ }^{\circ}$ texto $^{\circ}$ Indica fala mais baixa em relação ao contexto anterior e posterior de fala.

hhh Expiração audível.

(texto) Dúvidas na transcrição.

XXXX Indicam sílabas que não foram possíveis de se transcrever.

((texto)) Comentários do transcritor. 